\title{
Characterization of Yak Common Biofluids Metabolome by Means of Proton Nuclear Magnetic Resonance Spectroscopy
}

\author{
Chenglin Zhu ${ }^{1}$ (D), Cheng Li $^{2}$, Yaning Wang ${ }^{1}$ and Luca Laghi ${ }^{1, *(D)}$ \\ 1 Department of Agro-Food Science and Technology, University of Bologna, Piazza Goidanich 60, \\ 47521 Cesena, Italy; chenglin.zhu2@unibo.it (C.Z.); yaning.wang@studio.unibo.it (Y.W.) \\ 2 College of Food, Sichuan Agricultural University, Ya'an 625014, China; lichenglcp@163.com \\ * Correspondence: 1.laghi@unibo.it; Tel.: +39-0547-338106
}

Received: 14 February 2019; Accepted: 25 February 2019; Published: 2 March 2019

check for updates

\begin{abstract}
The aim of this study was to evaluate the metabolic profiles of yak (Bos grunniens) serum, feces, and urine by using proton nuclear magnetic resonance $\left({ }^{1} \mathrm{H}-\mathrm{NMR}\right)$, to serve as a reference guide for the healthy yak milieu. A total of 108 metabolites, giving information about diet, protein digestion, and energy generation or gut-microbial co-metabolism, were assigned across the three biological matrices. A core metabolome of 15 metabolites was ubiquitous across all biofluids. Lactate, acetate, and creatinine could be regarded as the most abundant metabolites in the metabolome of serum, feces, and urine, respectively. Metabolic pathway analysis showed that the molecules identified could be able to give thorough information about four main metabolic pathways, namely valine, leucine, and isoleucine biosynthesis; phenylalanine, tyrosine, and tryptophan biosynthesis; glutamine and glutamate metabolism; and taurine and hypotaurine metabolism.
\end{abstract}

Keywords: yak; Bos grunniens; serum; feces; urine; metabolomics; ${ }^{1} \mathrm{H}-\mathrm{NMR}$

\section{Introduction}

Metabolomics is a powerful approach to a biological system that aims to measure its low weight metabolites $(<900 \mathrm{Da})$. When untargeted, this characterization of the metabolic phenotype provides holistic information on the system under investigation because it allows the study of its biochemical responses to intrinsic (genetics, protein expression) or environmental (diet, gut microbiota) stimuli [1].

${ }^{1} \mathrm{H}-\mathrm{NMR}$ spectroscopy is one of the main platforms for metabolomics because the very simple sample preparation and highly reproducible molecule quantification counterbalance a sensitivity lower than the one granted by other platforms such as mass spectrometry. For this reason, ${ }^{1} \mathrm{H}-\mathrm{NMR}$ spectroscopy has been employed in domestic animals to obtain the metabolite profiles of several biofluids, among which urine [2,3], serum [4-6], tracheal wash, and exhaled breath condensate [7].

The yak (Bos grunniens) is regarded as a very peculiar species of ruminant because it represents the main sustaining food source for the people who live in the region around the Himalayas, with an altitude ranging from 2500 to $5500 \mathrm{~m}$ with no frost-free periods, and mostly above the tree line. The genetic adaptive evolution of the yak to the harsh conditions has led to larger heart and lungs, and a higher erythrocyte count, compared to the cattle (Bos taurus) [8], in addition to a more efficient energy harvesting and nitrogen utilization $[9,10]$. Therefore, the yak is considered an ideal model animal for studying adaptation mechanisms to harsh conditions represented by low temperatures and a paucity of oxygen and energy sources. Despite these peculiarities, the physiology of yak has rarely been studied through an "omics" approach. One reason for such a paucity of works may be the limited accessibility of the geographical areas where the yaks are bred, generally according to traditional 
practices. A few studies can be found focusing on yak milk [11-13] and its genome [8,14,15], with only one study that described the characteristics of yak meat [16]. The objective of the present study was to reduce this gap of information by characterizing, for the first time, the metabolome of yak serum, feces, and urine using ${ }^{1} \mathrm{H}-\mathrm{NMR}$. This study is meant as a reference guide for researchers wishing to apply a metabolomics approach to the yak. For this reason, in compliance with the guidelines outlined by the consortium COSMOS (Coordination of Standards in Metabolomics; http:/ / cosmos-fp7.eu/), the data have been made available on the open platform MetaboLights (study identifier: MTBLS841).

\section{Materials and Methods}

\subsection{Sampling of Biofluids}

Serum, feces, and urine sampling was carried out in a public abattoir located in the pastoral area of Litang County (altitude $4000 \mathrm{~m}$ ) at the end of August. This is the time of the year when yaks are traditionally slaughtered for meat, due to their optimal health conditions and highest weight.

Five specimens of male Jiulong yak (approximately three years of age, receiving no supplementation) were randomly selected for the current experiment. The yaks were transported to the abattoir (without modern slaughtering equipment), held in lairage for $24 \mathrm{~h}$ (water supplementation until $3 \mathrm{~h}$ before slaughtering), and then sacrificed according to the local traditional manual procedures of yak slaughter [17].

Upon slaughtering, $10 \mathrm{~mL}$ of blood was collected using disposable syringes $(10 \mathrm{~mL}$, without clotting activator, Jiangyin Fanmei Medical Device Co., Ltd., Jiangyin, Jiangsu, China) from the abdominal vein and immediately transferred to sterile conical tubes. Blood samples were left at room temperature for $45 \mathrm{~min}$ to allow coagulation without centrifugation, and subsequently, the serum was separated from the blood clot. Urine samples were collected by cystocentesis upon direct bladder visualization using a sterile syringe while feces were collected as the animals defecated during the slaughtering process. All the above-mentioned samples were transported in dry ice and stored at $-80{ }^{\circ} \mathrm{C}$ until analysis.

\subsection{Metabolomics Analysis of Biofluids}

We created an NMR analysis solution with 3-(trimethylsilyl)-propionic-2,2,3,3-d4 acid sodium salt (TSP) $10 \mathrm{mM}$ in $\mathrm{D}_{2} \mathrm{O}$, set at $\mathrm{pH} 7.00 \pm 0.02$ by means of $1 \mathrm{M}$ phosphate buffer, containing also $10 \mu \mathrm{L}$ of $\mathrm{NaN}_{3} 2 \mathrm{mM}$. TSP was employed as an NMR chemical-shift reference, while $\mathrm{NaN}_{3}$ avoided microbial proliferation.

Serum samples were prepared for ${ }^{1} \mathrm{H}-\mathrm{NMR}$ by thawing and centrifuging $1 \mathrm{~mL}$ of each sample for $15 \mathrm{~min}$ at $18,630 \mathrm{~g}$ and $4^{\circ} \mathrm{C}$. $500 \mu \mathrm{L}$ of supernatant was added to $100 \mu \mathrm{L}$ of NMR analysis solution. Urine samples were prepared for ${ }^{1} \mathrm{H}-\mathrm{NMR}$ by means of thawing and centrifuging them for $15 \mathrm{~min}$ at $18,630 \mathrm{~g}$ at $4{ }^{\circ} \mathrm{C}$. An amount of supernatant equal to $350 \mu \mathrm{L}$ was added to $350 \mu \mathrm{L}$ of bi-distilled water and to $200 \mu \mathrm{L}$ of NMR analysis solution. Fecal samples were prepared for ${ }^{1} \mathrm{H}-\mathrm{NMR}$ analysis by vortex mixing for $5 \mathrm{~min} 80 \mathrm{mg}$ of stool with $1 \mathrm{~mL}$ of deionized water. The obtained mixes were then centrifuged for $15 \mathrm{~min}$ at $18,630 \mathrm{~g}$ and $4{ }^{\circ} \mathrm{C}$, and $700 \mu \mathrm{L}$ of supernatant was added to $200 \mu \mathrm{L}$ of NMR analysis solution. Finally, each of the obtained samples was centrifuged again at the above conditions just before analysis.

${ }^{1} \mathrm{H}-\mathrm{NMR}$ spectra were recorded at $298 \mathrm{~K}$ with an AVANCE III spectrometer (Bruker, Milan, Italy) operating at a frequency of $600.13 \mathrm{MHz}$, equipped with the software Topspin 3.5. Following Zhu et al. [3]. The signals from broad resonances originating from large molecules were suppressed by a CPMG (Carr. Purcell. Meiboom. Gill) filter composed of 400 echoes with a $\tau$ of $400 \mu$ s and a $180^{\circ}$ pulse of $24 \mu \mathrm{s}$, for a total filter of $330 \mathrm{~ms}$. The water residual signal was suppressed by means of presaturation. This was done by employing the cpmgpr1d sequence, part of the standard pulse sequence library. Each spectrum was acquired by summing up 256 transients using $32 \mathrm{~K}$ data points over a $7184 \mathrm{~Hz}$ spectral window, with an acquisition time of $2.28 \mathrm{~s}$. 
Differences in water and fibers content among samples were taken into consideration by probabilistic quotient normalization [18], more reliable than the once more common normalization on creatinine. Spectra phase was manually adjusted in Topspin, while the subsequent adjustments were performed in R computational language by means of script developed in-house [19]. After the removal of the residual water signal, ${ }^{1} \mathrm{H}-\mathrm{NMR}$ spectra were baseline-corrected by means of peak detection, according to the "rolling ball" principle [20], implemented in the baseline R package [21]. The signals were assigned by comparing their chemical shift and multiplicity with Chenomx software library (Chenomx Inc., Edmonton, Alberta, Canada, ver 8.3), as detailed in Figures S1-S36.

In order to apply NMR as a quantitative technique [2], the recycle delay was set to $5 \mathrm{~s}$ by considering the relaxation time of the protons under investigation. Moreover, while TSP could be used as a reliable internal standard for urine and feces [22], the molecules of the first serum sample analyzed were quantified by means of an external standard, by taking advantage of the principle of reciprocity [23].

\subsection{Pathway Analysis}

Pathway analysis was performed using MetaboAnalyst 4.0 (https: / www.metaboanalyst.ca) [24], which organizes the information about biochemical pathways described in KEGG database (https: / /www.genome.jp). In detail, pathway analysis used high-quality KEGG metabolic pathways as the backend knowledgebase. The Pathway Analysis module combined results from powerful pathway enrichment analysis with pathway topology analysis to identify the most relevant pathways involved in the conditions under study.

\section{Results}

\section{1. ${ }^{1}$ H-NMR Spectra of Yak Serum, Feces, and Urine}

In the current study, we were able to identify and quantify 109 molecules across yak serum, feces, and urine, giving information about diet, protein digestion, energy generation, or gut-microbial co-metabolism. For readability, Tables 1 and 2 show the molecules that could be identified in all the biofluids, while the complete list is reported in Table S1. Typical ${ }^{1} \mathrm{H}-\mathrm{NMR}$ spectra of serum, feces, and urine are reported in Figures $1-3$, respectively.

Table 1. Metabolites identified by ${ }^{1} \mathrm{H}-\mathrm{NMR}$ in common among yak serum, feces, and urine.

\begin{tabular}{ccccc}
\hline Molecule & ppm & Functional Group & Multiplicity ${ }^{* *}$ & Source [25] ${ }^{* * *}$ \\
\hline 3-Hydroxybutyrate & 1.1863 & $\mathrm{CH}_{3}$ & $\mathrm{~d}$ & $\mathrm{E}$ \\
Acetate & 1.9071 & $\mathrm{CH}_{3}$ & $\mathrm{~s}$ & $\mathrm{P}$ \\
Alanine & 1.4675 & $\mathrm{CH}_{3}$ & $\mathrm{~d}$ & $\mathrm{P}$ \\
Creatine & 3.0222 & $\mathrm{CH}_{2}$ & $\mathrm{~s}$ & $\mathrm{P}$ \\
Dimethyl sulfone & 3.1391 & $\mathrm{CH}_{3}$ & $\mathrm{~s}, \mathrm{M}$ \\
Ethanol & 1.1699 & $\mathrm{CH}_{3}$ & $\mathrm{~s}$ & $\mathrm{E}, \mathrm{M}$ \\
Formate & 8.4446 & $\mathrm{CH}$ & $\mathrm{E}$ \\
Glucose & 3.2233 & $\mathrm{CH}_{2}$ & $\mathrm{dd}$ \\
Glycine & 3.5533 & $\mathrm{CH}_{2}$ & $\mathrm{~s}$ & $\mathrm{P}$ \\
Isoleucine & 1.0020 & $\mathrm{CH}_{3}-9$ & $\mathrm{~d}$ & $\mathrm{P}$ \\
Lactate & 4.1059 & $\mathrm{CH}_{2}$ & $\mathrm{dd}$ & $\mathrm{E}$ \\
Methanol & 3.3481 & $\mathrm{CH}_{3}$ & $\mathrm{~s}$ & $\mathrm{E}$ \\
Succinate & 2.3933 & $\mathrm{CH}_{2}$ & $\mathrm{~s}$ & $\mathrm{P}, \mathrm{E}$ \\
Tyrosine & 7.1776 & $\mathrm{CH}_{-3}$ & $\mathrm{~d}$ & $\mathrm{P}$ \\
Valine & 1.0206 & $\mathrm{CH}_{3}-7$ & $\mathrm{~d}$ & $\mathrm{P}$ \\
\hline
\end{tabular}

* Chemical shift of the signal employed for quantification; ** Splitting pattern of the signal ( $\mathrm{s}=$ singlet; $\mathrm{d}=$ doublet; $\mathrm{t}=$ triplet; $\mathrm{dd}=$ doublet of doublets); ${ }^{* * *}$ Main source of the molecules $(\mathrm{D}=$ dietary metabolites, $\mathrm{P}=$ protein and amino acid metabolism, $\mathrm{E}$ = energy metabolism, $\mathrm{M}$ = gut-microbial co-metabolism). 
Table 2. Concentration (median and interquartile range) of metabolites identified by ${ }^{1} \mathrm{H}-\mathrm{NMR}$ in common among yak serum, feces, and urine

\begin{tabular}{cccc}
\hline Molecules & Serum $(\mathbf{m m o l} / \mathbf{L})$ & Feces $(\mathbf{m m o l} / \mathbf{g})$ & Urine $(\mathbf{m m o l} / \mathbf{L})$ \\
\hline 3-Hydroxybutyrate & $1.40 \times 10^{-1}\left(3.56 \times 10^{-2}\right)$ & $1.52 \times 10^{-5}\left(1.30 \times 10^{-5}\right)$ & $1.28 \times 10^{-3}\left(7.54 \times 10^{-4}\right)$ \\
Acetate & $1.40 \times 10^{-1}\left(1.59 \times 10^{-1}\right)$ & $3.66 \times 10^{-2}\left(1.06 \times 10^{-2}\right)$ & $5.66 \times 10^{-4}\left(4.03 \times 10^{-4}\right)$ \\
Alanine & $2.78 \times 10^{-1}\left(1.27 \times 10^{-2}\right)$ & $5.16 \times 10^{-4}\left(3.25 \times 10^{-4}\right)$ & $2.14 \times 10^{-4}\left(4.23 \times 10^{-5}\right)$ \\
Creatine & $2.01 \times 10^{-1}\left(2.12 \times 10^{-1}\right)$ & $1.91 \times 10^{-5}\left(1.88 \times 10^{-5}\right)$ & $4.00 \times 10^{-2}\left(1.80 \times 10^{-2}\right)$ \\
Dimethyl sulfone & $1.23 \times 10^{-2}\left(4.15 \times 10^{-3}\right)$ & $1.29 \times 10^{-5}\left(1.07 \times 10^{-5}\right)$ & $6.15 \times 10^{-4}\left(1.40 \times 10^{-4}\right)$ \\
Ethanol & $4.69 \times 10^{-3}\left(2.74 \times 10^{-3}\right)$ & $7.15 \times 10^{-5}\left(2.98 \times 10^{-5}\right)$ & $2.62 \times 10^{-4}\left(3.81 \times 10^{-5}\right)$ \\
Formate & $1.78 \times 10^{-2}\left(5.69 \times 10^{-3}\right)$ & $1.17 \times 10^{-4}\left(2.43 \times 10^{-5}\right)$ & $2.50 \times 10^{-4}\left(1.70 \times 10^{-4}\right)$ \\
Glucose & $1.37\left(5.97 \times 10^{-1}\right)$ & $3.51 \times 10^{-4}\left(5.47 \times 10^{-5}\right)$ & $8.33 \times 10^{-4}\left(4.09 \times 10^{-4}\right)$ \\
Glycine & $5.11 \times 10^{-1}\left(3.91 \times 10^{-1}\right)$ & $1.77 \times 10^{-4}\left(7.46 \times 10^{-6}\right)$ & $8.52 \times 10^{-4}\left(5.64 \times 10^{-4}\right)$ \\
Isoleucine & $4.35 \times 10^{-2}\left(1.62 \times 10^{-2}\right)$ & $6.20 \times 10^{-5}\left(1.39 \times 10^{-4}\right)$ & $1.33 \times 10^{-4}\left(7.24 \times 10^{-5}\right)$ \\
Lactate & $7.25\left(5.46 \times 10^{-1}\right)$ & $5.57 \times 10^{-5}\left(5.13 \times 10^{-5}\right)$ & $9.37 \times 10^{-4}\left(1.87 \times 10^{-4}\right)$ \\
Methanol & $7.14 \times 10^{-3}\left(1.78 \times 10^{-3}\right)$ & $9.12 \times 10^{-5}\left(4.36 \times 10^{-5}\right)$ & $3.95 \times 10^{-5}\left(2.32 \times 10^{-5}\right)$ \\
Succinate & $2.01 \times 10^{-1}\left(4.09 \times 10^{-2}\right)$ & $1.12 \times 10^{-4}\left(4.47 \times 10^{-5}\right)$ & $9.15 \times 10^{-5}\left(7.46 \times 10^{-5}\right)$ \\
Tyrosine & $2.53 \times 10^{-2}\left(1.22 \times 10^{-2}\right)$ & $1.16 \times 10^{-4}\left(6.81 \times 10^{-5}\right)$ & $1.23 \times 10^{-3}\left(2.26 \times 10^{-5}\right)$ \\
Valine & $1.48 \times 10^{-1}\left(1.14 \times 10^{-2}\right)$ & $1.91 \times 10^{-4}\left(5.42 \times 10^{-5}\right)$ & $1.22 \times 10^{-4}\left(3.45 \times 10^{-5}\right)$ \\
\hline
\end{tabular}
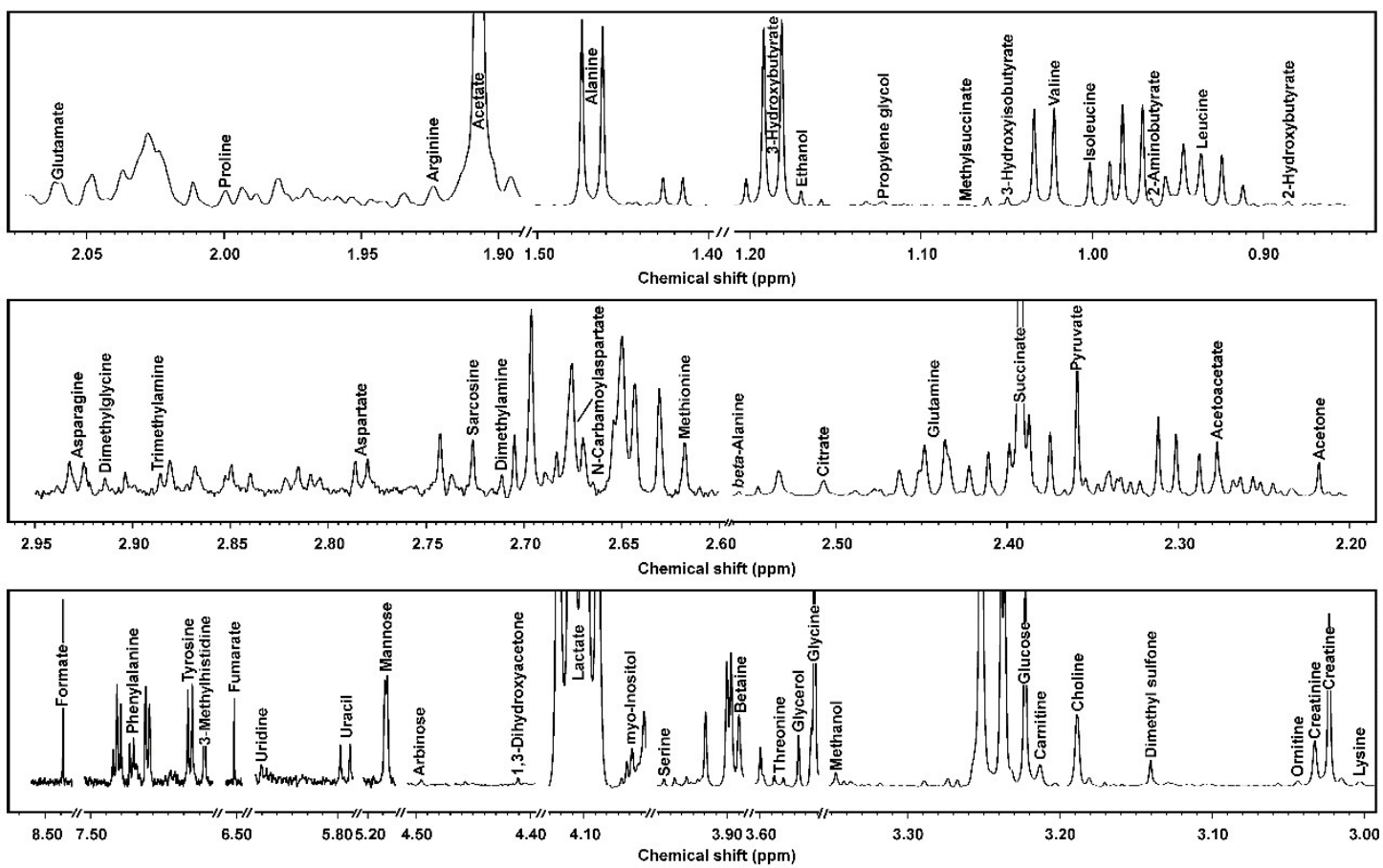

Figure 1. ${ }^{1} \mathrm{H}-\mathrm{NMR}$ signals from yak serum, representative of those registered in the present work. The name of each molecule appears over the signal used for its quantification. To ease the reader's visual inspection, for each portion the spectrum with a convenient signal-to-noise ratio has been selected. 

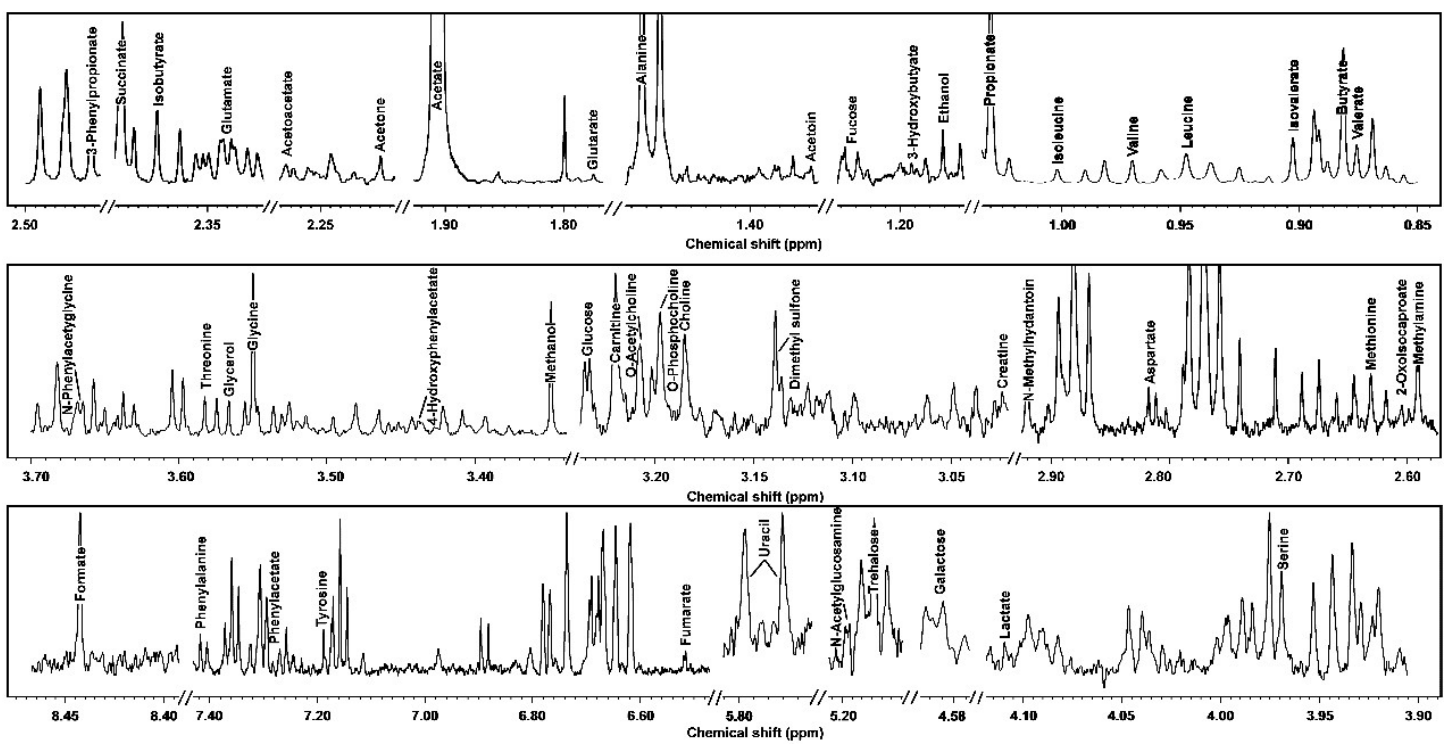

Figure 2. ${ }^{1} \mathrm{H}-\mathrm{NMR}$ signals from yak feces, representative of those registered in the present work. The name of each molecule appears over the signal used for its quantification. To ease the reader's visual inspection, for each portion the spectrum with a convenient signal-to-noise ratio has been selected.
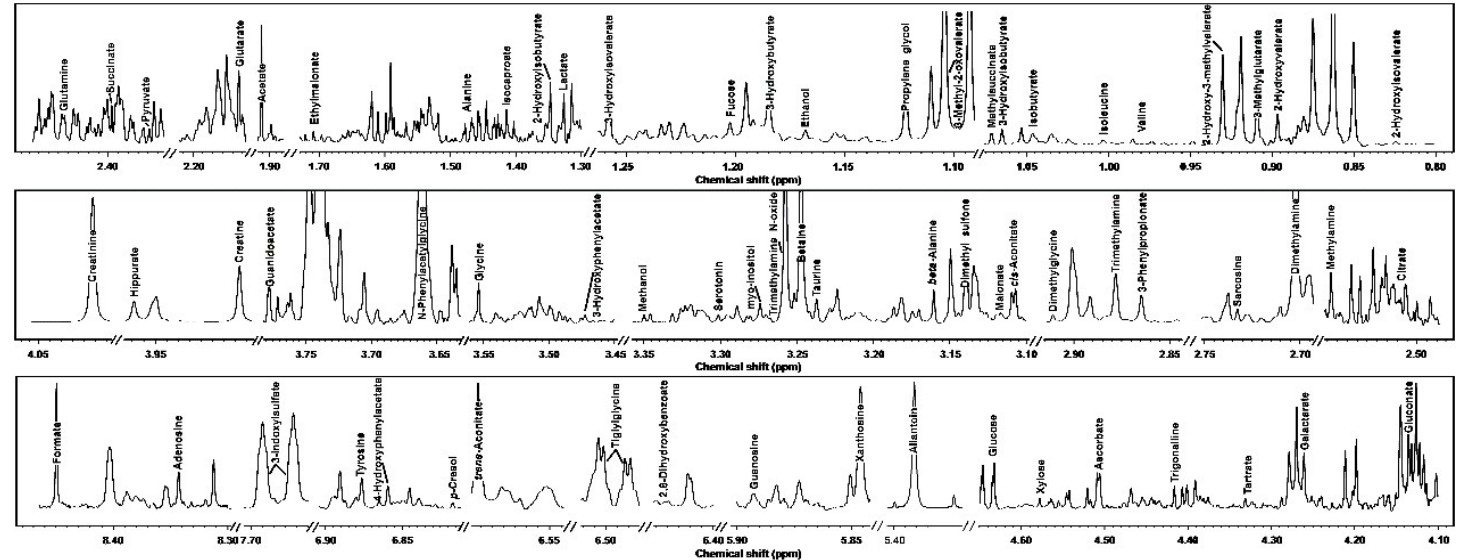

Figure 3. ${ }^{1} \mathrm{H}-\mathrm{NMR}$ signals from yak urine, representative of those registered in the present work. The name of each molecule appears over the signal used for its quantification. To ease the reader's visual inspection, for each portion the spectrum with a convenient signal-to-noise ratio has been selected.

By means of ${ }^{1} \mathrm{H}-\mathrm{NMR}$ we were able to identify and quantify 56 molecules in serum, 49 in feces, and 68 in urine-nearly a twofold increase in comparison to previous works on cattle $[4,26]$. The area of the signals of the molecules overall assigned in serum, feces, and urine accounted on average for $85.04 \%, 87.04 \%$, and $61.40 \%$ of the total spectral area, respectively. Among the molecules quantified, 15 were in common among the three biofluids, as shown in Figure 4. 


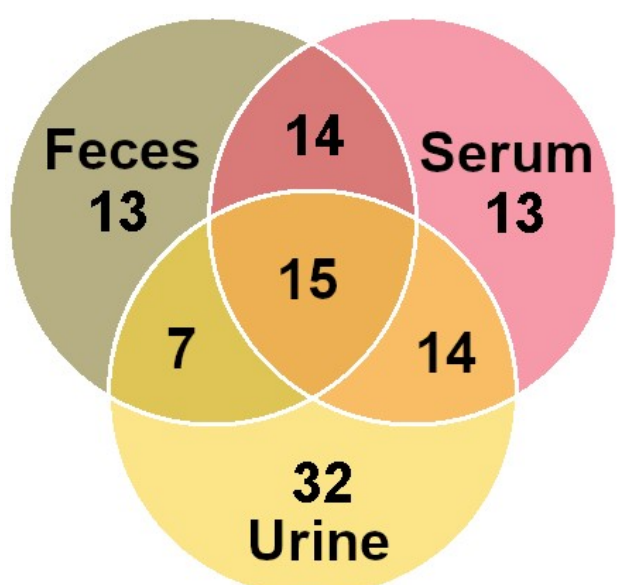

Figure 4. Venn diagram showing unique and shared metabolites among yak serum, urine, and feces. The number of metabolites is listed in each of the diagram components.

\subsection{Molecule Distribution by Class}

As shown in Figure 5, in serum and feces most of the molecules that were detected belong to the class of organic acids and their derivatives (47.09\% and $86.92 \%$, respectively), while amino acids, peptides, and analogs were mostly represented in the urine. As reported in detail in the supplementary material, lactate was the most concentrated molecule detected in serum $(41.83 \%)$, followed by glucose $(27.95 \%)$. In feces, the most concentrated molecule detected was acetate $(49.04 \%)$, followed by propionate $(17.58 \%)$ and butyrate $(8.55 \%)$. In urine, the most concentrated substances detected were creatinine (28.69\%), N-phenylacetylglycine (28.50\%), and hippurate (13.28\%).

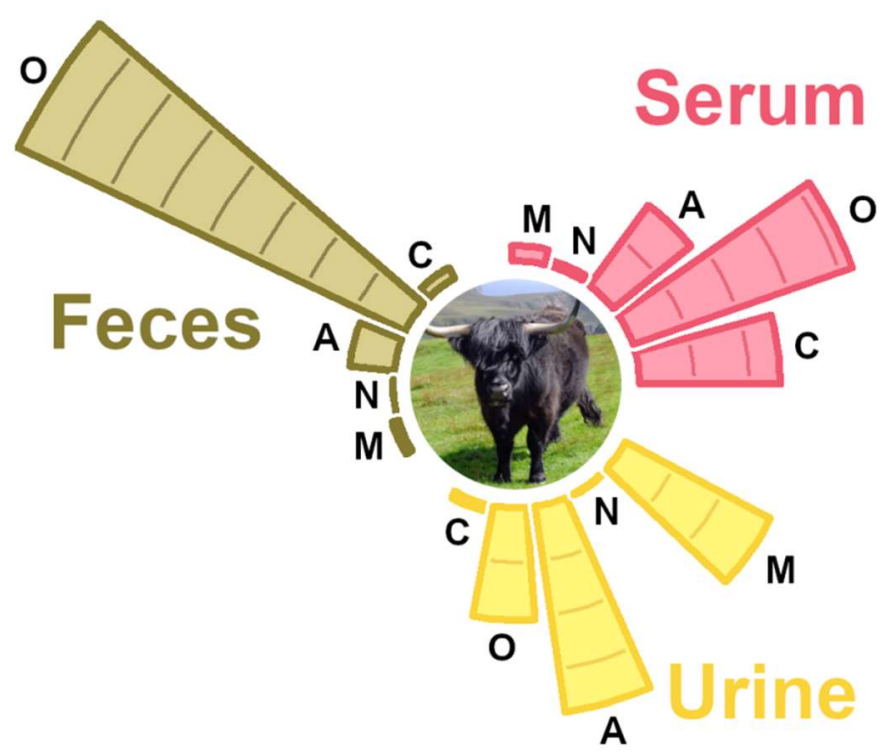

Figure 5. The relative abundance of the classes of molecules assigned in serum, feces, and urine metabolome. As a reference, the lines inside the bars are written in $10 \%$ steps. $\mathrm{C}=$ carbohydrates and derivatives, $\mathrm{O}=$ organic acids and derivatives, $\mathrm{A}=$ amino acids, peptides, and derivatives, $\mathrm{N}=$ nucleosides, nucleotides, and analogs, $\mathrm{M}=$ miscellaneous.

\subsection{Pathway Analysis}

We wanted to understand which metabolic pathway could be described in sufficient detail by the molecules identified in the three biofluids studied. For this purpose, a pathway analysis was performed by means of the MetaboAnalyst platform on each biofluid, as detailed in Figure 6. Overall, three pathways were described with an impact as high as 1 , namely valine, leucine, and isoleucine 
biosynthesis; phenylalanine, tyrosine, and tryptophan biosynthesis; and glutamine and glutamate metabolism. In addition, the first two were described in high detail throughout each of the biofluids studied. Five more pathways were described with an impact higher than 0.5. These pathways included alanine, aspartate, and glutamate metabolism; glycine, serine, and threonine metabolism; synthesis and degradation of ketone bodies; D-glutamine, glyoxylate, and dicarboxylate metabolism; and taurine and hypotaurine metabolism.

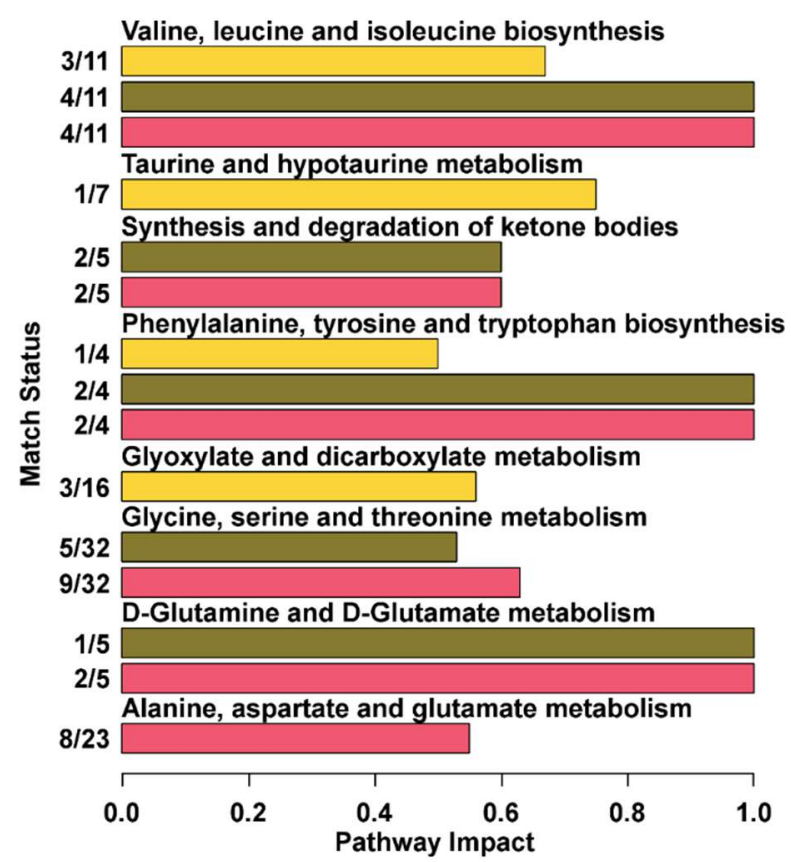

Figure 6. Metabolic pathways evidenced by enrichment analysis based on the metabolites detected in serum, feces, and urine (impact value $>0.5$ [27]).

\section{Discussion}

\subsection{Yak Serum Metabolome}

To our knowledge, the metabolome of yak serum has never been described before in literature. The metabolome of serum has been studied before in cattle, a closely related species, but only with a focus on the biomarkers of specific diseases or viruses, such as milk fever [5], footrot [6], Mycobacterium tuberculosis [4], and Mycobacterium avium subsp. paratuberculosis [28].

Lactate is the most abundant low-weight metabolite we were able to observe in the yak serum. In cattle, its presence has been mainly attributed to ruminal microflora [29]. Its presence in yak serum plays a special role, because its high concentration, together with pyruvate, is a direct consequence of the adaptation to low oxygen levels connected to altitude [30-32]. In fact, hypoxia prompts a shift towards anaerobic energy generation through an active withdrawal of pyruvate from the TCA cycle towards lactate production [33-35]. Another explanation for the presence of lactate in the serum samples is that the blood was collected after the slaughter of the animal, and so lactate could have been remarkably concentrated due to stress. Finally, the sample preparation did not include a centrifugation step, so the lactate may have also come from the erythrocytes that were damaged during freezing and thawing.

Glucose was the second most abundant molecule we quantified in yak serum. Experiments on rats suggest that this molecule could offer another direct way to follow the consequences of altitude on yak metabolism. Glucose utilization has been found to increase with altitude, because alternative energy generation pathways, such as those involving proteins, can be insufficient for the maintenance of glycemia, especially after exercise [31]. 


\subsection{Yak Feces Metabolome}

The metabolic composition of fecal extracts provides a window for elucidating the complex metabolic interplay between mammals and their intestinal ecosystem. Moreover, the metabolite profile can yield information on a range of gut conditions [36]. To the best of the authors' knowledge, feces from cattle have been observed from the microbiome point of view [37], but never from a metabolomics perspective. Interestingly, considering the total concentration of the molecules detected in the feces equal to $100,75.17 \%$ was represented by the short chain fatty acids (SCFAs) acetate, propionate, and butyrate. SCFAs are major products of the microbial fermentation of fiber polysaccharides in the rumen, which may play an important role in the efficient harvesting of energy from plants [38]. This efficiency seems to be mediated by ruminal microbiome selection, as recently observed by Zhang et al. [37], who compared animals that were genetically adapted and non-adapted to high altitudes. Notably, Zhang et al. also found that the rumen microbiome of high-altitude ruminants showed a significant up-regulation of amino acids metabolism. This finding could be coherent with our pathway analysis, where the most important pathways described by the yak feces metabolome indeed entail amino acid metabolism.

\subsection{Yak Urine Metabolome}

As plasma sampling is invasive by nature, and fecal extracts inherently vary in composition with the relative abundance of microbial-mammalian metabolites, urine is regarded as the most appropriate biofluid for the purposes of metabonomic analysis [25].

The most abundant metabolite we quantified in yak urine was creatinine. This molecule is synthesized in connection to the absorption of creatine phosphate by the muscles, then released to the serum, and cleared by kidneys. In cattle, this molecule has been found to be proportional to muscle activity, with specific reference to heart and respiration rates [39], but this is higher in yak than in cattle [8].

The second and third most abundant metabolites we quantified in yak urine were hippurate and $N$-phenylacetylglycine, which are regarded as urinary metabolomic biomarkers of the response to hypobaric hypoxia, according to Koundal et al. [40]. Koundal et al. built a mouse model to illustrate how mice urinary metabolomics were changing in response to hypobaric hypoxia. Taurine metabolism and TCA were highlighted as important pathways that might have contributed to hypobaric hypoxia-induced pathophysiology, which is in accordance with our findings. Hippurate and $N$-phenylacetylglycine are sorted as metabolites relating to gut microflora metabolism and they also demonstrated that lowered urinary hippurate and $N$-phenylacetylglycine indicate decreased gut microflora.

In ruminants, the purine derivative allantoin is regarded as a biomarker of nitrogen clearance, which is generated from uric acid by uricase. In response to the harsh forage environment, yaks expel through urine a lower amount of purine derivatives [9], with mechanisms to recycle nitrogen, which are probably linked to the reduced degradation of nucleic acids by rumen microbiota [41].

\section{Conclusions}

To the best of our knowledge, this is the first work where ${ }^{1} \mathrm{H}-\mathrm{NMR}$ has been employed to study yak biofluids from a metabolomics perspective. Due to the small number of samples investigated, the results presented here should be regarded as preliminary. Nevertheless, we were able to characterize as many as 56, 49 , and 68 metabolites in serum, feces, and urine, respectively, which is almost two times more than previously reported for cattle. The most concentrated metabolites in the three biofluids were found related to some of the biological reasons for the adaptation of yak to the ecological niche represented by extreme altitudes. Future research focusing on the comparison between wild and captive yaks could be useful to even better characterize the metabolome of the yak. 
Supplementary Materials: The following are available online at http://www.mdpi.com/2218-1989/9/3/41/s1, Figures: Supplemental_Material.docx, Tables: Supplemental_Material.docx and Supplemental_Material.xlsx

Author Contributions: Conceptualization, C.Z., C.L. and L.L.; methodology, C.Z. and L.L.; formal analysis, C.Z., L.L. and Y.W.; writing-original draft preparation, C.Z. and L.L.

Funding: This research received no external funding.

Acknowledgments: Chenglin Zhu gratefully acknowledges financial support from the Chinese Scholarship Council (Grant No. 201606910076).

Conflicts of Interest: The authors declare no conflict of interest.

\section{References}

1. Nicholson, J.K.; Lindon, J.C.; Holmes, E. "Metabonomics": understanding the metabolic responses of living systems to pathophysiological stimuli via multivariate statistical analysis of biological NMR spectroscopic data. Xenobiotica 1999, 29, 1181-1189. [CrossRef] [PubMed]

2. Laghi, L.; Zhu, C.; Campagna, G.; Rossi, G.; Bazzano, M.; Laus, F. Probiotic Supplementation in Trained Trotter Horses: Effect on Blood Clinical Pathology Data and Urine Metabolomic Assessed in Field. J. Appl. Physiol. 2018, 125, 654-660. [CrossRef] [PubMed]

3. Zhu, C.; Faillace, V.; Laus, F.; Bazzano, M.; Laghi, L. Characterization of trotter horses urine metabolome by means of proton nuclear magnetic resonance spectroscopy. Metabolomics 2018, 14, 106. [CrossRef]

4. Chen, Y.; Wu, J.; Tu, L.; Xiong, X.; Hu, X.; Huang, J.; Xu, Z.; Zhang, X.; Hu, C.; Hu, X.; et al. 1H-NMR Spectroscopy Revealed Mycobacterium tuberculosis Caused Abnormal Serum Metabolic Profile of Cattle. PLoS One 2013, 8, e74507. [CrossRef] [PubMed]

5. Sun, Y.; Xu, C.; Li, C.; Xia, C.; Xu, C.; Wu, L.; Zhang, H. Characterization of the serum metabolic profile of dairy cows with milk fever using 1 H-NMR spectroscopy. Vet. Q. 2014, 34, 159-163. [CrossRef] [PubMed]

6. Wang, J.; Wang, H.; Zhu, K.; Xu, C.; Shu, S.; Zheng, J.; Sun, L. Nuclear magnetic resonance-based serum metabolic profiling of dairy cows with footrot. J. Vet. Med. Sci. 2016, 78, 1421-1428. [CrossRef]

7. Bazzano, M.; Laghi, L.; Zhu, C.; Magi, G.E.; Serri, E.; Spaterna, A.; Tesei, B.; Laus, F. Metabolomics of tracheal wash samples and exhaled breath condensates in healthy horses and horses affected by equine asthma. J. Breath Res. 2018, 12, 46015. [CrossRef] [PubMed]

8. Zhang, L.; Wu, J.; Wang, X.; Liu, B.; Ma, B. Isolation of metallothionein genes and in silico structural characterization of their proteins Using molecular modeling from Yak (Bos grunniens). Biochem. Genet. 2012, 50,585-599. [CrossRef] [PubMed]

9. Shang, Z.; Liang, J.B.; Long, R.; Wang, H.; Ding, L.; Guo, X. Comparison of Nitrogen Metabolism in Yak (Bos grunniens) and Indigenous Cattle (Bos taurus) on the Qinghai-Tibetan Plateau. Asian-Australasian J. Anim. Sci. 2011, 24, 766-773. [CrossRef]

10. Zhou, J.W.; Liu, H.; Zhong, C.L.; Degen, A.A.; Yang, G.; Zhang, Y.; Qian, J.L.; Wang, W.W.; Hao, L.Z.; Qiu, Q.; et al. Apparent digestibility, rumen fermentation, digestive enzymes and urinary purine derivatives in yaks and Qaidam cattle offered forage-concentrate diets differing in nitrogen concentration. Livest. Sci. 2018, 208, 14-21. [CrossRef]

11. Wen, Y.; He, Q.; Ding, J.; Wang, H.; Hou, Q.; Zheng, Y.; Li, C.; Ma, Y.; Zhang, H.; Kwok, L.Y. Cow, yak, and camel milk diets differentially modulated the systemic immunity and fecal microbiota of rats. Sci. Bull. 2017, 62, 405-414. [CrossRef]

12. Yang, Y.; Zheng, N.; Zhao, X.; Zhang, Y.; Han, R.; Yang, J.; Zhao, S.; Li, S.; Guo, T.; Zang, C.; et al. Metabolomic biomarkers identify differences in milk produced by Holstein cows and other minor dairy animals. J. Proteomics 2016, 136, 174-182. [CrossRef] [PubMed]

13. Qu, S.; Barrett-Wilt, G.; Fonseca, L.M.; Rankin, S.A. A profile of sphingolipids and related compounds tentatively identified in yak milk. J. Dairy Sci. 2016, 99, 5083-5092. [CrossRef] [PubMed]

14. Zhang, Y.; Liu, J.; Zhang, D.; Hasegawa, M.; Liu, W.; Zhang, J.; Ma, T.; Cao, C.; Lenstra, J.A.; Zang, X.; et al. The yak genome and adaptation to life at high altitude. Nat. Genet. 2012, 44, 946-949. [CrossRef]

15. Zhang, Q.; Gong, J.; Wang, X.; Wu, X.; Li, Y.; Ma, Y.; Zhang, Y.; Zhao, X. Molecular cloning, bioinformatics analysis and expression of insulin-like growth factor 2 from tianzhu white yak,bos grunniens. Int. J. Mol. Sci. 2014, 15, 504-524. [CrossRef] [PubMed] 
16. Luo, X.L.; Tong, Z.B.; Wei, Y.P.; Zhao, X.Q. Meat characteristics of Qinghai yak and semi-wild yak. Anim. Sci. J. 2006, 77, 230-234. [CrossRef]

17. Wiener, G.; Han, J.; Long, R. The yak, 2nd ed.; FAO Regional Office for Asia and the, Pacific, Ed.; FAO Regional Office for Asia and the Pacific: Bangkok, 2003; ISBN 92-5-104965-3.

18. Dieterle, F.; Ross, A.; Schlotterbeck, G.; Senn, H. Probabilistic quotient normalization as robust method to account for dilution of complex biological mixtures. Application in1H NMR metabonomics. Anal. Chem. 2006, 78, 4281-4290. [CrossRef] [PubMed]

19. Ihaka, R.; Gentleman, R. R: A Language for Data Analysis and Graphics. J. Comput. Graph. Stat. 1996, 5, 299-314. [CrossRef]

20. Kneen, M.A.; Annegarn, H.J. Algorithm for fitting XRF, SEM and PIXE X-ray spectra backgrounds. Nucl. Instruments Methods Phys. Res. Sect. B Beam Interact. with Mater. Atoms 1996, 109-110, 209-213. [CrossRef]

21. Liland, K.H.; Almøy, T.; Mevik, B.H. Optimal choice of baseline correction for multivariate calibration of spectra. Appl. Spectrosc. 2010, 64, 1007-1016. [CrossRef] [PubMed]

22. Winning, H.; Larsen, F.H.; Bro, R.; Engelsen, S.B. Quantitative analysis of NMR spectra with chemometrics. J. Magn. Reson. 2008, 190, 26-32. [CrossRef] [PubMed]

23. Hoult, D.I. The principle of reciprocity. J. Magn. Reson. 2011, 213, 344-346. [CrossRef] [PubMed]

24. Li, C.; Soufan, O.; Chong, J.; Xia, J.; Bourque, G.; Li, S.; Caraus, I.; Wishart, D.S. MetaboAnalyst 4.0: towards more transparent and integrative metabolomics analysis. Nucleic Acids Res. 2018, 46, W486-W494. [CrossRef]

25. Escalona, E.E.; Leng, J.; Dona, A.C.; Merrifield, C.A.; Holmes, E.; Proudman, C.J.; Swann, J.R. Dominant components of the Thoroughbred metabolome characterised by $1 \mathrm{H}$-nuclear magnetic resonance spectroscopy: A metabolite atlas of common biofluids. Equine Vet. J. 2015, 47, 721-730. [CrossRef] [PubMed]

26. Bertram, H.C.; Yde, C.C.; Zhang, X.; Kristensen, N.B. Effect of dietary nitrogen content on the urine metabolite profile of dairy cows assessed by nuclear magnetic resonance (NMR)-based metabolomics. J. Agric. Food Chem. 2011, 59, 12499-12505. [CrossRef] [PubMed]

27. Xia, J.; Wishart, D.S.; Valencia, A. MetPA: A web-based metabolomics tool for pathway analysis and visualization. In Bioinformatics; 2011; Volume 27, pp. 2342-2344.

28. De Buck, J.; Shaykhutdinov, R.; Barkema, H.W.; Vogel, H.J. Metabolomic profiling in cattle experimentally infected with mycobacterium avium subsp. paratuberculosis. PLoS One 2014, 9, e111872. [CrossRef] [PubMed]

29. Trabi, M.; Keller, M.D.; Jonsson, N.N. NMR-based metabonomics of bovine blood: An investigation into the effects of long term storage on plasma samples. Metabolomics 2013, 9, 1041-1047. [CrossRef]

30. Gold, A.; Johnson, T.; Costello, L. Effects of altitude stress on mitochondrial function. Am. J. Physiol. Content 1973, 224, 946-949. [CrossRef] [PubMed]

31. Messier, F.M.; Le Moyec, L.; Santi, C.; Gaston, A.-F.; Triba, M.N.; Roca, E.; Durand, F. The impact of moderate altitude on exercise metabolism in recreational sportsmen: a nuclear magnetic resonance metabolomic approach. Appl. Physiol. Nutr. Metab. 2017, 42, 1135-1141. [CrossRef] [PubMed]

32. Tissot van Patot, M.C.; Serkova, N.J.; Haschke, M.; Kominsky, D.J.; Roach, R.C.; Christians, U.; Henthorn, T.K.; Honigman, B. Enhanced leukocyte HIF-1 $\alpha$ and HIF-1 DNA binding in humans after rapid ascent to $4300 \mathrm{~m}$. Free Radic. Biol. Med. 2009, 46, 1551-1557. [CrossRef] [PubMed]

33. Firth, J.D.; Ebert, B.L.; Ratcliffe, P.J. Hypoxic regulation of lactate dehydrogenase A: Interaction between hypoxia-inducible factor 1 and cAMP response elements. J. Biol. Chem. 1995, 270, 21021-21027. [CrossRef] [PubMed]

34. Banchero, N. Cardiovascular Responses to Chronic Hypoxia. Annu. Rev. Physiol. 1987, 204, 3133-3139. [CrossRef] [PubMed]

35. Kim, J.W.; Tchernyshyov, I.; Semenza, G.L.; Dang, C.V. HIF-1-mediated expression of pyruvate dehydrogenase kinase: A metabolic switch required for cellular adaptation to hypoxia. Cell Metab. 2006, 3, 177-185. [CrossRef] [PubMed]

36. Jacobs, D.M.; Deltimple, N.; van Velzen, E.; van Dorsten, F.A.; Bingham, M.; Vaughan, E.E.; van Duynhoven, J. $1 \mathrm{H}$ NMR metabolite profiling of feces as a tool to assess the impact of nutrition on the human microbiome. NMR Biomed. 2008, 21, 615-626. [CrossRef] [PubMed]

37. Huang, X.; Qiu, Q.; Wang, W.; Wang, L.; Zhang, Z.; Zhao, F.; Zhou, J.; Long, R.; Shi, P.; Xu, D.; et al. Convergent Evolution of Rumen Microbiomes in High-Altitude Mammals. Curr. Biol. 2016, 26, 1873-1879. [CrossRef] 
38. Liang, G.; Chen, Y.; Guan, L.L.; Kong, R.S.G.; Stothard, P. Transcriptome profiling of the rumen epithelium of beef cattle differing in residual feed intake. BMC Genomics 2016, 17, 592. [CrossRef]

39. Graf, G.C.; Petersen, W.E. Changes in Respiration and Heart Rates, Body Temperatures, Plasma Lactic Acid Levels and Plasma Creatinine Levels Caused by Stress in Dairy Cattle. J. Dairy Sci. 1953, 36, 1036-1048. [CrossRef]

40. Kaur, T.; Mazumder, A.; Gandhi, S.; Khushu, S.; Koundal, S. “Omics” of High Altitude Biology: A Urinary Metabolomics Biomarker Study of Rats Under Hypobaric Hypoxia. Omi. A J. Integr. Biol. 2015, 19, 757-765. [CrossRef]

41. Vercoe, J.E. Urinary allantoin excretion and digestible dry-matter intake in cattle and buffalo. J. Agric. Sci. 1976, 86, 613-615. [CrossRef]

(C) 2019 by the authors. Licensee MDPI, Basel, Switzerland. This article is an open access article distributed under the terms and conditions of the Creative Commons Attribution (CC BY) license (http:/ / creativecommons.org/licenses/by/4.0/). 